\title{
Comparisons between Synchronizing Circuits to Control Algorithms for Single-Phase Active Converters
}

\author{
H. Carneiro ${ }^{1}$, L. F. C. Monteiro ${ }^{2}$, J. L. Afonso ${ }^{1}$ \\ 1 - University of Minho - Industrial Electronics Department, Campus de Azurém 4800-058 - Guimarães, Portugal. \\ 2 - PROQUALI, Estrada do Galeão 2730 / 201, Ilha do Governador - 21931-582, Rio de Janeiro, Brazil. \\ E-mail:Helder.carneiro@gmail.com,lfcm@lemt.ufrj.br,jla@dei.uminho.pt
}

\begin{abstract}
This paper presents a comparative analysis between synchronizing circuits applied to control algorithms for singlephase active converters. One of these synchronizing circuits corresponds to the single-phase PLL (Phase Locked Loop), implemented in $\alpha-\beta$ coordinates, whereas the other one corresponds to the E-PLL (Enhanced PLL). These synchronizing circuits are compared in several aspects as processing and settling time and memory space requirements. Moreover, the performance of a single-phase back-to-back converter is also presented, with its control algorithm based on these Synchronizing Circuits. Each one of the control algorithms were implemented in a DSP microprocessor TMS320F2812F from Texas Instruments. Simulation and experimental results, through a back-to-back converter prototype, are presented.
\end{abstract}

\section{INTRODUCTION}

The proliferation of nonlinear loads in residences, offices and industries has contributed to increase the harmonic pollution observed in the power grid. Moreover, the harmonic current-components consumed by these nonlinear loads results in harmonic voltage-drop on the supply line impedances, which deteriorates the waveform of the voltages delivered to the load [1]. There are also other events as voltage sags or voltage swells that are resulted, respectively, from connection or disconnection of large loads [2] [3]. All of these events are the most responsible ones for the observed problems in sensitive loads as improperly shut down, reduced lifetime, malfunction, and so others.

Power quality problems can be overcome, in real time, through the utilization of "Custom Power" devices. In this paper a back-to-back converter is used, which is composed by two power converters that are connected in series and in shunt with the power grid. The shunt converter consists in an active rectifier that injects or absorbs energy from the power grid, in order to keep the dc-link voltage regulated. The series converter is responsible to compensate the major power quality problems related with the system voltages, such that the voltage delivered to the load remain regulated and with low harmonic distortion.

To control these converters, control algorithms based on the instantaneous power theory ( $p-q$ Theory) are applied [4] together with a synchronizing circuit. The synchronizing circuit is responsible to produce, in real time, sinusoids that are synchronized with the fundamental component of the system voltage. Thus it can be observed its importance, since the voltage produced by the series converter depends, directly, on the generated sinusoid by the synchronizing circuit.

Due to the importance of the synchronizing circuit, this paper investigates two different topologies. The first one corresponds to the single-phase PLL (Phase - Locked - Loop) [4] [5] [6] [7] [8], implemented in $\alpha-\beta$ coordinates, whereas the other one corresponds to the E-PLL (Enhanced PLL) [9] [10] [11].

The comparison involving these PLL topologies is focused in processing and settling time and memory space requirements. Both controllers where implemented in a DSP microprocessor TMS320F2812F from Texas Instruments. Being a real time processing system, computing speed and memory usage, as well as the settling time are important issues. These characteristics must be enhanced; moreover, they most provide compensated voltages that comprises with the power quality standards [12]. Simulation and experimental results, through a back-to-back converter prototype, are presented.

\section{HARDWARE CONFIGURATION}

As aforementioned in this paper and indicated in Fig. 1, the back-to-back converter is composed by two power converters that are connected in series and in shunt with the power grid. A step-down transformer $(5 \mathrm{kVA}-230 \mathrm{~V} / / 115 \mathrm{~V})$ is used to provide galvanic isolation between the power converters and the power grid. Another step-down transformer, with the same characteristics, is used to connect the shunt converter with the power grid. The series converter is directly connected with the power grid.

Each one of the single-phase power converters is composed by two branches (4 IGBTs with anti-parallel diodes) from model Semikron SKM-50GB063D [13]. The IGBTs of this power module present as main features a collector-emitter voltage of $600 \mathrm{~V}$ and a collector current of $50 \mathrm{~A}$ (peak value).

The dc-link is composed by three $4700 \mu \mathrm{F}$ capacitors connected in series, which corresponds to an equivalent capacitor of, approximately, $1566.67 \mu \mathrm{F}$. Each one of these capacitors presents a dc-voltage rating of $450 \mathrm{~V}$.

The RLC coupling filter of the series converter is composed by a $15 \Omega$ resistor $\left(\mathrm{R}_{\mathrm{fs}}\right)$, an $8.8 \mu \mathrm{F}$ capacitor $\left(\mathrm{C}_{\mathrm{fs}}\right)$, and an air-core inductor of $0.6 \mathrm{mH}\left(\mathrm{L}_{\mathrm{fs}}\right)$. The RLC filter of the 


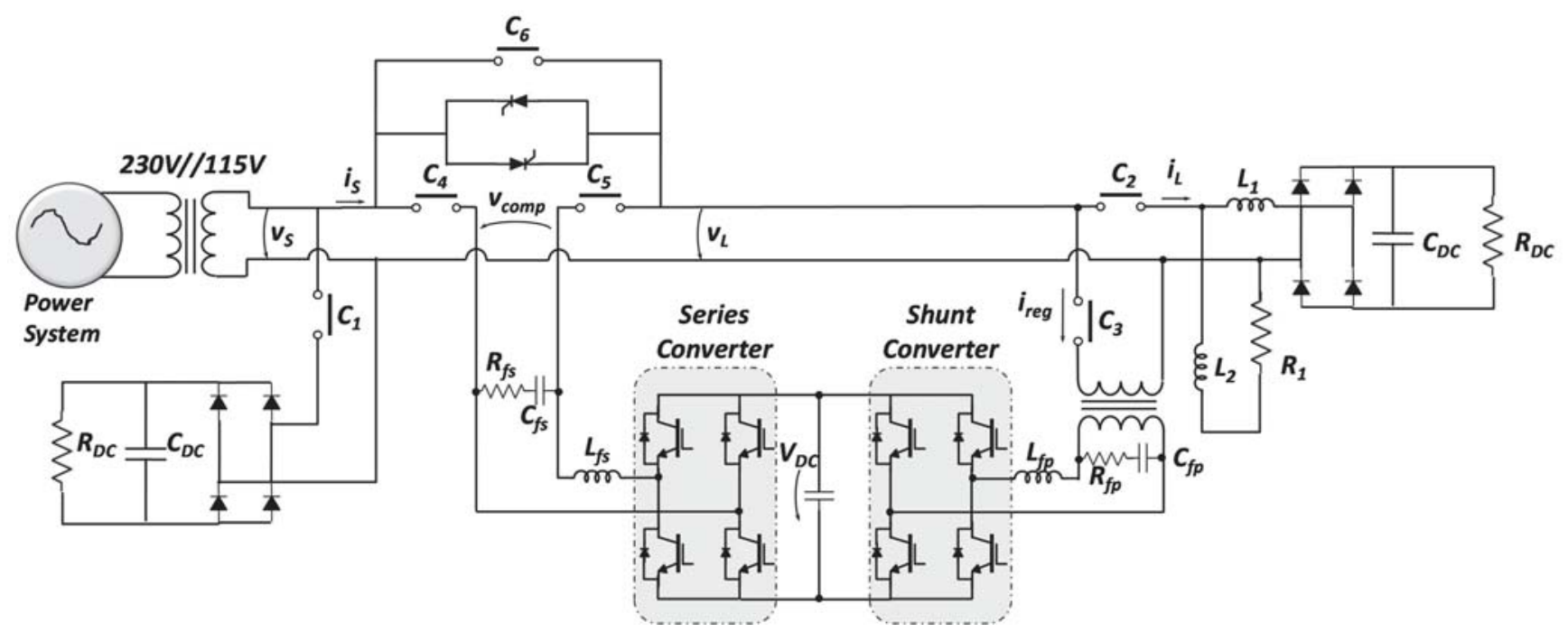

Fig. 1. Electrical Diagram of the Single-Phase Back-to-Back Converter.

shunt converter is comprehended by a $0.6 \mathrm{mH}$ inductor $\left(\mathrm{L}_{\mathrm{fp}}\right)$, an $4 \Omega$ resistor $\left(R_{\mathrm{fp}}\right)$, and an $2.2 \mu \mathrm{F}$ capacitor $\left(\mathrm{C}_{\mathrm{fs}}\right)$.

The nonlinear load consists of a single-phase diode rectifier, with a RC Load on the dc-side $\left(C_{D C}=4,7 \mathrm{mF}\right.$ and $\mathrm{R}_{\mathrm{DC}}=25 \Omega$ ). To smooth the current waveform, it is used a $3 \mathrm{mH}$ inductor $\left(\mathrm{L}_{1}\right)$. There is also a linear load, connected in shunt with the nonlinear load, composed by a $30 \Omega$ resistor $\left(\mathrm{R}_{1}\right)$ and a $650 \mu \mathrm{H}$ inductor $\left(\mathrm{L}_{2}\right)$.

A diode rectifier, similar to the nonlinear load, is used to increase the harmonic distortion of the supply voltage. This rectifier is located between the transformer, connected in series with the power grid, and the series converter.

A soft-start circuit was implemented to suppress the lack of electric isolation of a coupling transformer that is present in the majority of series converters [13]. It also acts as a protection system to overloads and short-circuits. Moreover, contactors are employed to connect the shunt $\left(C_{3}\right)$ and series $\left(C_{4}, C_{5}, C_{6}\right)$ power converters, as well as to connect the loads with the electrical system $\left(C_{1}, C_{2}\right)$.

The supply voltage is represented in Fig. 1 as being $v_{S}$, and the load voltage is $v_{L}$. The produced voltage by the series converter is represented as $v_{\text {comp }}$. The load and source currents are represented as $i_{L}$ and $i_{S}$, respectively. The controlled current $\left(i_{r e g}\right)$ is produced by the shunt converter in order to regulate the DC link voltage.

\section{CONTROLler OF THE BACK-TO-BACK CONVERTER}

As introduced in section I the controller of the back-toback converter is constituted by control algorithms to determine the reference signals to be produced by the power converters, plus switching algorithms to command the IGBTs. The control algorithms to determine the reference signals are comprehended by a synchronizing circuit, an algorithm to determine the compensating currents and an algorithm to determine the compensating voltages. In Fig. 2 is shown a block diagram that represents the control algorithms to determine the reference signals. The control algorithms denominated in Fig. 2 as "Current-Reference Algorithm" and
"Voltage-Reference Algorithm" are based on the concepts involving the instantaneous power theory $(p-q$ Theory) with some simplifications. Hereafter, these control algorithms are described, and, in sequence, the investigated synchronizing circuits are introduced.

\section{A. Current-Reference Algorithm}

Since there are no power sources on the dc side of the power converter, a controller that keeps the dc-link voltage regulated has to be implemented. It is worth to notice that, with only this control algorithm, the shunt converter does not provide active filtering. In this case, the shunt converter can be considered as an active rectifier. Based on the dc-link voltage $\left(v_{D C}\right)$, the control signal $p_{\text {Reg }}$ is determined as described as follows:

$p_{\text {Reg }}=\left(v_{\text {Ref }}-v_{D C}\right) \cdot\left(k_{p_{-} d c}+\frac{k_{i \_d c}}{s}\right)$.

The control signal $p_{\text {Reg }}$ can be understood as an amount of energy, per time unit, that is drained or injected by the shunt converter in order to keep the dc-link voltage regulated. As indicated in (1), the control signal $v_{\text {Ref }}$ corresponds to the

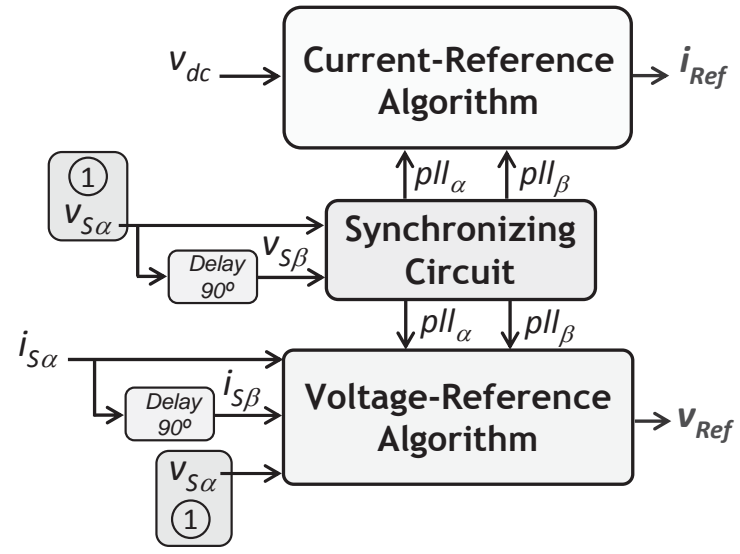

Fig. 2. General control scheme of the algorithms that determine the reference signals. 
reference value of the dc-link voltage, and the control signals $p d c$ and $i d c$ represent, respectively, to the proportional and integral gains of the PI-Controller.

In sequence, the mathematical methodology to determine the reference signal $i_{\text {Ref }}$ is described. Since this algorithm is based on the $p-q$ Theory, consider that is necessary to determine the reference signals in $\alpha \beta$ coordinates $\left(i_{\text {Ref } \alpha}, i_{\text {Ref } \beta}\right)$ as described as follows:

$\left[\begin{array}{cc}i_{\text {Ref }} & \alpha \\ i_{\text {Ref }} & \beta\end{array}\right]=\frac{1}{p l l_{\alpha}^{2}+p l l_{\beta}^{2}} \cdot\left[\begin{array}{cc}p l l_{\alpha} & p l l_{\beta} \\ p l l_{\beta} & -p l l_{\alpha}\end{array}\right] \cdot\left[\begin{array}{c}p_{\text {Reg }} \\ 0\end{array}\right]$,

where, the signals $p \|_{\alpha}$ and $p \|_{\beta}$ are generated by the synchronizing circuit. For now, it is assumed that these signals are sinusoidal waveforms, with unitary amplitude, and are in phase with the fundamental frequency of the control signals $v_{s \alpha}$ and $v_{s \beta}$, respectively. After some simplifications in equation (2), $i_{\text {Ref } \alpha}$ and $i_{\text {Ref } \beta}$ are given by:

$i_{\text {Ref } \alpha}=\frac{p l l_{\alpha} \cdot p_{\text {Reg }}}{p l l_{\alpha}^{2}+p l l_{\beta}^{2}}=p l l_{\alpha} \cdot p_{\text {Reg }}$

$i_{\text {Ref } \beta}=\frac{p l l_{\beta} \cdot p_{R e g}}{p l l_{\alpha}^{2}+p l l_{\beta}^{2}}=p l l_{\beta} \cdot p_{R e g}$.

Indeed, since the control signals $p I_{\alpha}$ and $p \|_{\beta}$ are sinusoids with unitary amplitude and $p \|_{\alpha}$ leads $0 \quad p \|_{\beta}$, it can be assumed that the sum of their square values is equal to one.

Based on the Clarke Transformation [13] [14] and assuming a "fictitious" three-phase three-wire system, the control signal $i_{\text {Ref }}$ is given by:

$\left[\begin{array}{c}i_{R e f} \\ 0 \\ 0\end{array}\right]=\sqrt{\frac{2}{3}} \cdot\left[\begin{array}{cc}1 & 0 \\ -1 / 2 & \sqrt{3} / 2 \\ -1 / 2 & -\sqrt{3} / 2\end{array}\right] \cdot\left[\begin{array}{cc}i_{\operatorname{Ref}} & \alpha \\ i_{\operatorname{Ref}} & \beta\end{array}\right]$.

As it can be observed in (4), $i_{\text {Ref }}$ is only associated with

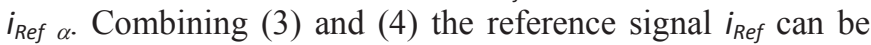
determined in a very simple way as described as follows:

$i_{\text {Ref }}=\sqrt{\frac{2}{3}} \cdot p l l_{\alpha} \cdot p_{\text {Reg }}$

Based on the aforementioned e planation, it can be noted that the computational effort to determine $i_{R e f}$ is directly related with the synchronizing circuit and with the PIController. In sequence, the control algorithm that determines the reference voltage $v_{\text {Ref }}$ is described.

\section{olt ge-Reference Algorithm}

As illustrated in Fig. 3, this algorithm presents as inputs the signals derived from the source current $\left(i_{S}\right)$ in $\alpha \beta$ coordinates $\left(i_{s \alpha}, i_{s \beta}\right)$, the control signal obtained from the system voltage $\left(v_{s \alpha}\right)$, plus the signals generated by the synchronizing circuit $\left(p / l_{\alpha}, p l_{\beta}\right)$. In this algorithm there is also a control block that determines control voltages with the objective to damp resonance phenomena, denominated as "Damping

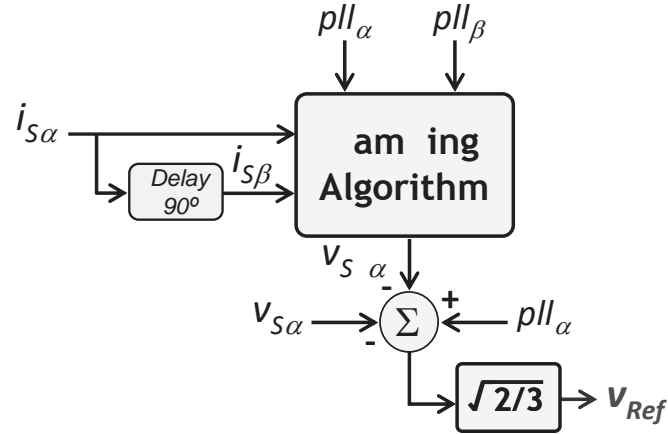

Fig. 3. Diagram blocks of the Voltage-Reference Algorithm

Algorithm" block. Indeed, as described in [6], instability problems due to the resonance phenomena, involving the passive filters and the system impedance, may occur. In order to enhance the overall system stability, an au iliary algorithm can be added to the controller of the series converter. In sequence, it is described a mathematical methodology, based on the $p-q$ Theory, to determine the control signal $v_{S} \alpha$.

In a similar way of the presented one in (4) the control signals $i_{s \alpha}$ and $v_{s \alpha}$ are determined, respectively, from the source current $\left(i_{S}\right)$ and system voltage $\left(v_{S}\right)$ as described as follows:

$i_{\alpha}=\sqrt{\frac{3}{2}} \cdot i$

$v_{\alpha}=\sqrt{\frac{3}{2}} \cdot v$

The signal $i_{s \beta}$ is shifted by 0 from $i_{s \alpha}$. The control signals $i_{s \alpha}$ and $i_{s \beta}$, together with to the ones generated by the synchronizing circuit $\left(p\left\|_{\alpha}, p\right\|_{\beta}\right)$ are applied to calculate the real and imaginary powers as described as follows:

$\left[\begin{array}{l}p \\ q\end{array}\right]=\left[\begin{array}{cc}p l l_{\alpha} & p l l_{\beta} \\ p l l_{\beta} & -p l l_{\alpha}\end{array}\right] \cdot\left[\begin{array}{l}i_{\alpha} \\ i_{\beta}\end{array}\right]$.

In sequence, the control signal $i_{S} \alpha$ is determined according to the following equation:

$\left[\begin{array}{c}i_{h \alpha} \\ 0\end{array}\right]=\frac{1}{p l l_{\alpha}^{2}+p l l_{\beta}^{2}} \cdot\left[\begin{array}{cc}p l l_{\alpha} & p l l_{\beta} \\ p l l_{\beta} & -p l l_{\alpha}\end{array}\right] \cdot\left[\begin{array}{c}p \\ q\end{array}\right]$,

where, the powers $p$ and corresponds to the oscillating components of the real $(p)$ and imaginary ( ) powers, and they can be obtained through high-pass filters. The direct product involving the control signal $i_{S \alpha}$ by a gain denominated as results in the harmonic controlled-voltage $\left(v_{S} \alpha\right)$. The gain can be understood as a resistance only for the harmonic components. Further details involving the damping algorithm are described in [14].

Finally, the reference voltage $\left(v_{R e f}\right)$ is determined as indicated in Fig. 3. hen $v_{\text {Ref }}$ is produced by the series converter, it is e pected that power quality problems 


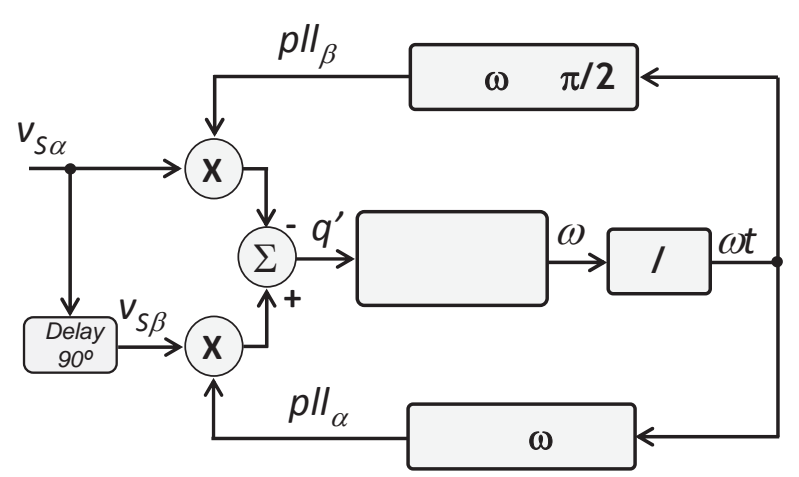

Fig. . ingle- hase hase- ocke - oo .

obser e at the s stem oltages can be com ensate an moreo er it is e ecte that roblems relate ith resonance henomena can be a oi e. $\mathrm{n}$ se ence are resente the s nchroni ing circ its aforementione in section .

\section{Single-Phase Phase-Locked-Loop (Single-Phase PLL)}

his $s$ nchroni ing circ it is similar to the one im lemente to three- hase s stems ith some sim lifications as intro ce in . n Fig. is ill strate the single- hase in $\alpha \beta$ coor inates.

As in icate in Fig. the fee back signals $p I_{\alpha}$ an $p \|_{\beta}$ are $b$ ilt $b$ the circ it st sing the time integral of o t $\mathrm{t} \omega$ of the - ontroller. hese fee back signals ha e nit am lit e an $p \|_{\alpha}$ lea s $p \|_{\beta}$. he circ it becomes stable onl if the a erage com onent of the fictitio $s$ imaginar $o$ er reaches ero al e $\bar{q}^{\prime}=0$ an has minimi e lo -fre enc oscillating ortions in its oscillating com onent $\tilde{q}^{\prime}$. nce the circ it is stabili e the a erage al e of $q^{\prime}$ is ero an ith this the hase angle of the $\mathrm{f} n$ amental fre enc is reache. At this con ition the fee back signal $p l_{\alpha}$ becomes in hase ith the $f \mathrm{n}$ amental com onent of the control signal $v_{s \alpha}$. F rther e lanations in ol ing this for three- hase $\mathrm{s}$ stems are resente in

ereafter it follo s some sim lation res lts relate ith the single- hase . nitiall in this case test the in $t$ signal corres on $\mathrm{s}$ to $v_{s \alpha}=100 \cdot \sin (\omega t+45 \%)$. At $t=2.0 \mathrm{~s}$ the hase angle of the in $t$ signal is mo ifie $\mathrm{s}$ ch that the mo ifie in $t$ signal corres on $\mathrm{s}$ to $v_{s \alpha}=100 \cdot \sin (\omega t+90 \%)$.

$\mathrm{n}$ Fig. is sho $\mathrm{n}$ the erformance of the single- hase tracking the in $\mathrm{t}$ signal $v_{s \alpha}=100 \cdot \sin (\omega t+45 \circ)$. he starts at $t=0.1 \mathrm{~s}$. After $\mathrm{c}$ cles the control signal $p / l_{\alpha}$ tracks the in $\mathrm{t}$ signal $v_{s \alpha}$.

Fig. ill strates the control signal $p / l_{\alpha}$ tracking the in $t$ signal $v_{S \alpha}$ at the transient $t=2.0 \mathrm{~s}$ hen the hase angle of the in $t$ signal $\varphi_{\text {Ref }}$ is increase from to . As it can be seen in Fig. at $t=2.07 \mathrm{~s}$ the control signal $p / l_{\alpha}$ tracks again the in $t$ signal $v_{S \alpha}$.

ase on these reliminar sim lation res lts it can be note the feasibilit of this $s$ nchroni ing circ it. $t$ can also be seen in literat re the erformance of this $n$ er orse con itions than the resente ones in this a er.

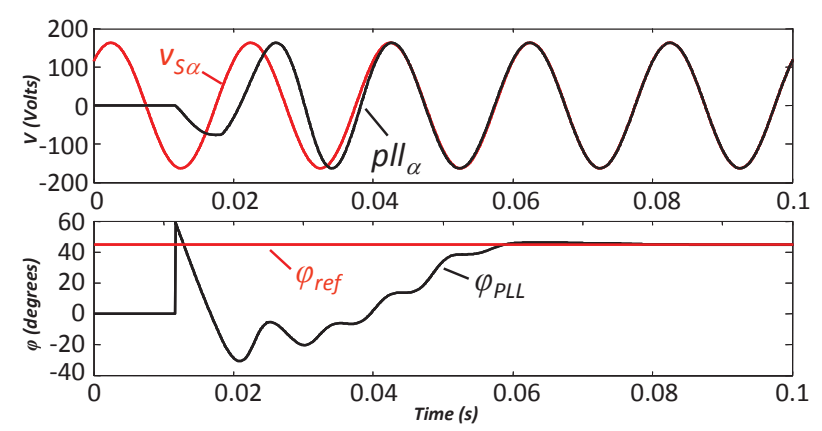

Fig. . erformance of the single- hase to track the in t signal $v_{s \alpha}$.
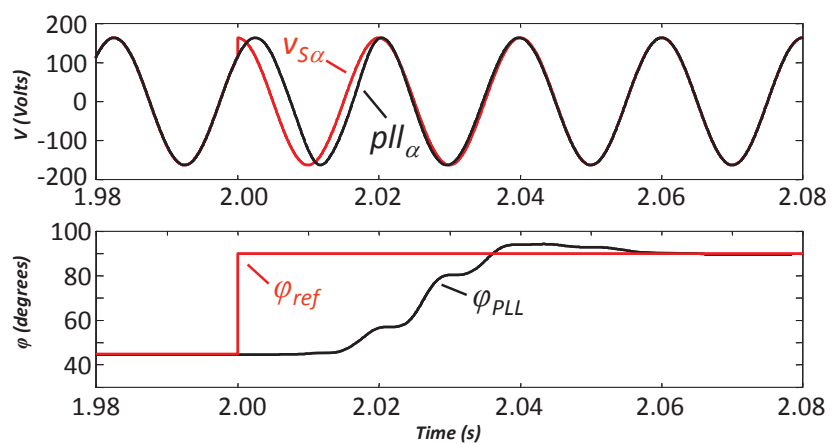

Fig. . erformance of the single- hase to track the in $t$ signal $v_{s}$ hen the hase angle $\varphi_{\text {ref }}$ is mo ifie from to

\section{Single - Phase Enhanced PLL}

$n$ Fig. the ro ose algorithm is sho $n$ as a block iagram of the nhance riginall the com rises a control loo to etermine the am lit e an another control loo that e tracts the fre enc an hase angle of the in $t$ signal. herefore ifferent from the the - reall etermines the $\mathrm{f} n$ amental com onent of the in t signal hich one is com rehen e b its am lit $e$ fre enc an hase angle.

nfort natel it is esire that the generate signals $b$ the $\mathrm{s}$ nchroni ing circ it resent constant am lit e. $\mathrm{h} \mathrm{s}$ the generate signals ro ce b the Ep/l $E_{\alpha} \|_{\beta}$ can not be irectl se . n Fig. the single- hase is sho $\mathrm{n}$. e $t$ it follo $s$ a brief escri tion in ol ing the str ct re ith the a lie mo ification.

he error signal $e$ corres on $\mathrm{s}$ to the total ist rbance bet een the in $\mathrm{t}$ signal $v_{s \alpha}$ an the generate one $\mathrm{b}$ the $E p I_{\alpha}$. he fee back signals $\cos (\omega t)$ an $\sin (\omega t)$ are

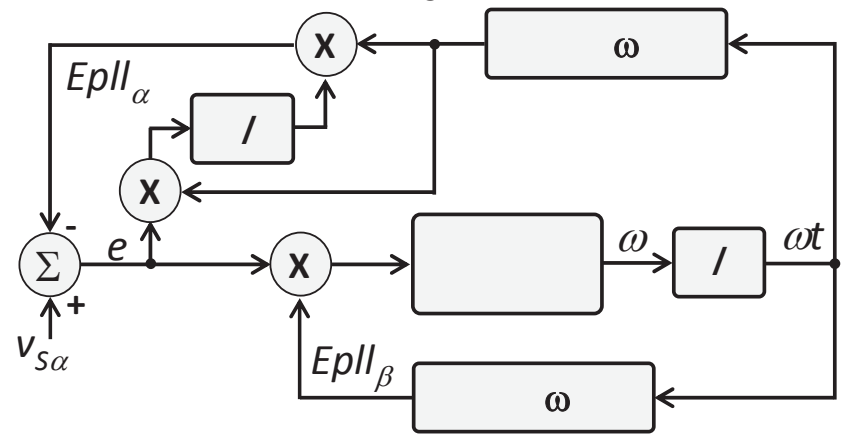

Fig. . ingle- hase nhance 

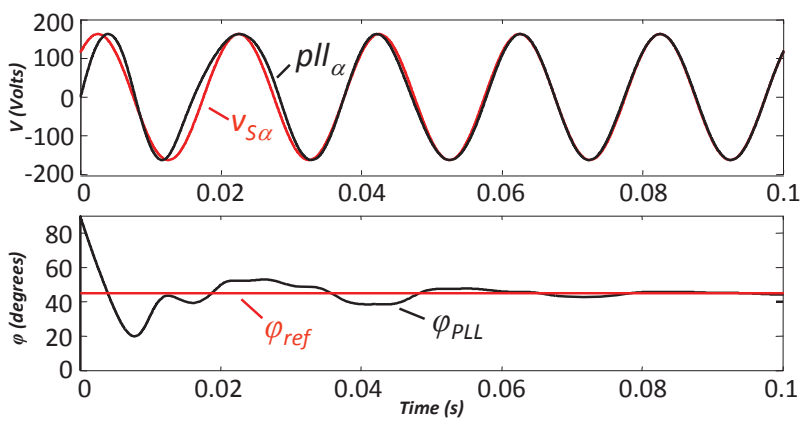

Fig. 8. Performance of the single-phase EPLL to track the input signal $\left(v_{s \alpha}\right)$
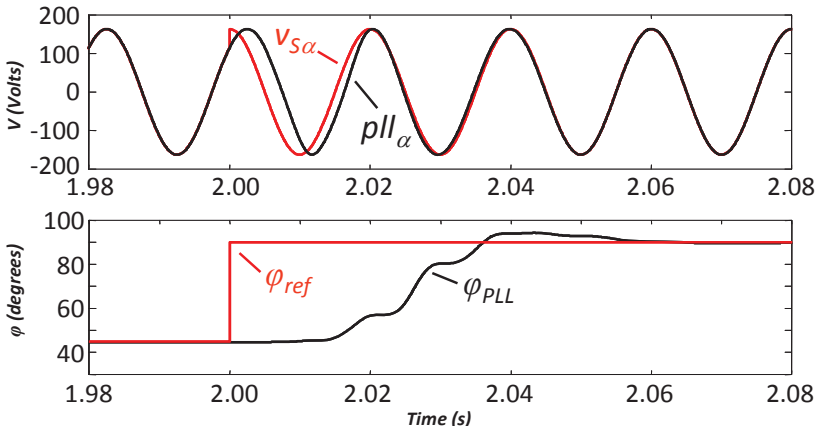

Fig. 9. Performance of the single-phase EPLL to track the input signal $\left(v_{s \alpha}\right)$, when the phase angle $\left(\varphi_{\text {ref }}\right)$ is modified from $45^{\circ}$ to $90^{\circ}$

$b$ ilt sing the time integral of $\mathrm{o} t \mathrm{t} \omega$ of the ontroller. he circ it becomes stable onl if the a erage com onent of the error signal $e$ reaches ero al e. nce this circ it is stabili e the control signal Ep/l ${ }_{\alpha}$ tracks the in t signal $v_{s \alpha}$ an as a conse ence the hase angle of the $\mathrm{f} \mathrm{n}$ amental fre enc is reache. $\mathrm{F}$ rther e lanations in ol ing the are resente in n Fig. an Fig. are resente the sim lation res lts ith the same test cases a lie to the single- hase

$$
\text { V. } \quad \mathrm{R} \quad \mathrm{A} \text { R }
$$

he s nchroni ing circ its ere im lemente on the $\mathrm{e}$ as nstr ments $\quad 3$ F $F$ D micro rocessor. For memor re irements assessment ariables si e as meas re . $\mathrm{n}$ able the ariables $\mathrm{n}$ mber an si e are sho $\mathrm{n}$ an total memor $\mathrm{s}$ ace eman $\mathrm{e}$ for each $\mathrm{s}$ nchroni ing circ it is calc late .

$$
\text { A }
$$

\begin{tabular}{|c|c|c|}
\hline & $\mathrm{R}$ & $\mathrm{R}$ \\
\hline \multirow{2}{*}{ Type } & \multicolumn{2}{|c|}{ Memory Space } \\
\hline & Single-Phase PLL & Enhanced PLL \\
\hline double & $(4 \times 32) 128$ bits & $(6 \times 32) 192$ bits \\
\hline long int & $(14 \times 32) 448$ bits & $(17 \times 32) 672$ bits \\
\hline long int array & $(640 \times 32) 20480$ bits & - \\
\hline TOTAL & 21096 bits & 864 bits \\
\hline
\end{tabular}

The system voltage is sampled 640 times each grid period. These instantaneous values are stored in a 640 position array, which is used to create the $90^{\circ}$ shifted signal used in the Single-Phase PLL. This causes the Single-Phase PLL

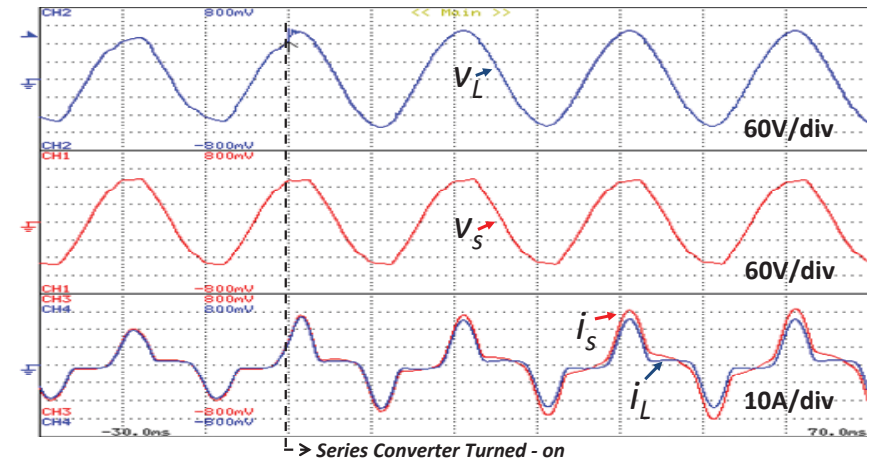

Fig. 10. Voltages and currents of the system when the Series Active Conditioner with single-phase PLL is turned on.

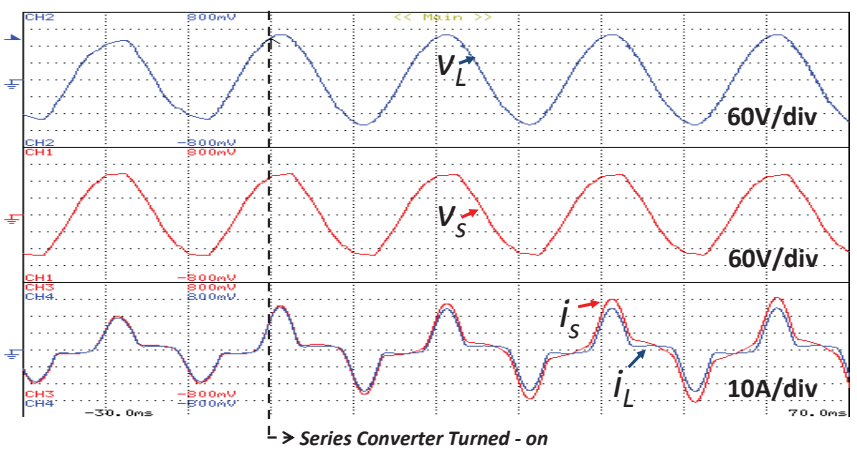

Fig. 11. Voltages and currents of the system when the Series Active Conditioner with EPLL is turned on.

memory requirements to be wider than the EPLL. Given the vast amount of memory available in the selected microprocessor, this matter has a small importance.

The processing speed of each synchronizing circuits was also measured. This was made by counting the system clock cycles of the synchronizing circuit routine. The all control system has a $31.25 \mu$ s available processing time, actuating 640 times by grid cycle. The DSP TMS320F2812F system clock frequency was set at $135 \mathrm{MHz}$. The EPLL synchronizing circuit takes 2197 system clock cycles, which corresponds to $16.27 \mu \mathrm{s}$. It occupies $52 \%$ of the control system routine available time. The Three-Phase Adapted PLL takes 1511 system clock cycles, $11.19 \mu \mathrm{s}$, which corresponds to $35.8 \%$ of the available processing time.

To evaluate performance characteristics, the Series Active Conditioner was set to compensate the load voltage distortion. For each proposed algorithm, the load voltage $\left(v_{L}\right)$ presents a $7.9 \%$ THD, and a RMS value of $102.2 \mathrm{~V}$ before compensation. In Fig. 10 is shown the systems voltages and currents when the Conditioner starts with the Single-Phase PLL. $v_{L}$ THD drops to $2.1 \%$, and the RMS value rises to 114.3 V. In Fig. 11 is showed the same transient, being the EPLL the synchronizing circuit. $v_{L}$ THD drops to $2.1 \%$ and RMS value is of $114.3 \mathrm{~V}$. The two synchronizing circuits present the same behavior in this transient analysis. In both cases it can be seen that $i_{S}$ rises, in order to regulate the DC link voltage.

Another transient was applied to the system. It consisted in closing contactor $\mathrm{C}_{1}$ (see Fig. 1,) thus connecting the shunt 


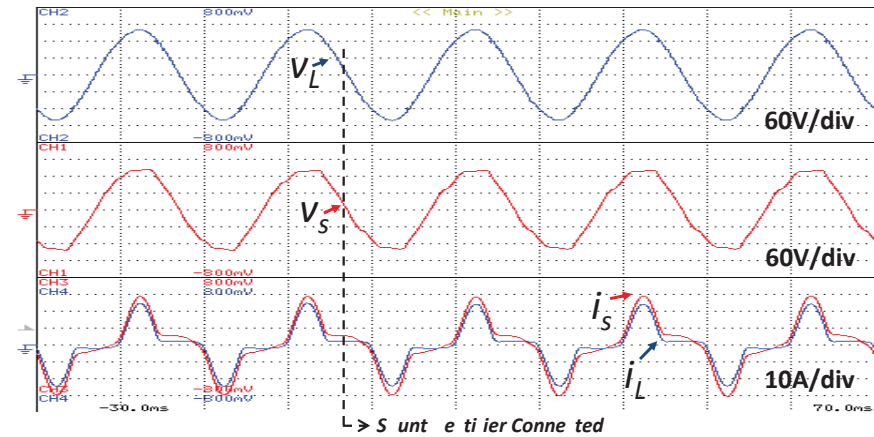

Fig. 12. Series Active Conditioner with Single-Phase PLL under the connection of the shunt rectifier. Dot line marks the connection of the rectifier.

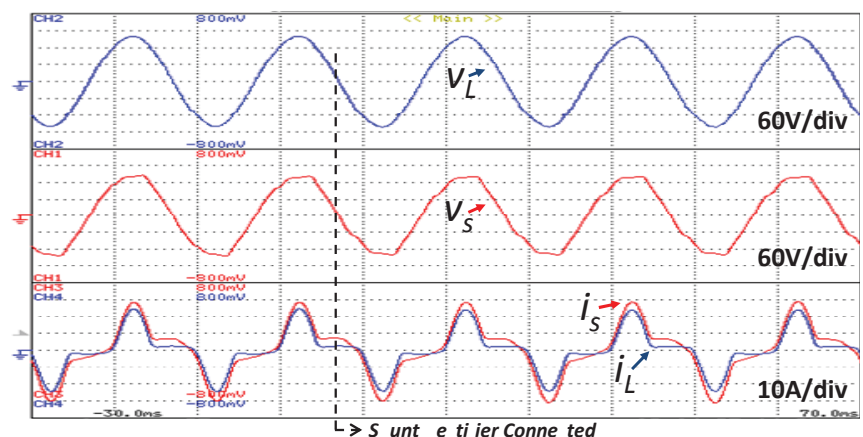

Fig. 13. Series Active Conditioner with Single-Phase PLL under the connection of the shunt rectifier. Dot line marks the connection of the rectifier.

rectifier to the system, with the series converter turned on. This action would degrade $v_{L}$ THD to $8.8 \%$, and the RMS value to $99.7 \mathrm{~V}$ if there was no compensation. In Fig. 12 can be seen the system voltages and currents when the rectifier is connected with the Conditioner already compensating, with the Single-Phase PLL algorithm. It can be seen that $v_{S}$ becomes more distorted, but $v_{L}$ maintains a low THD. It is of $1.8 \%$ and the RMS voltage is at $115 \mathrm{~V}$. The same values where obtained when the same transient was applied to the system with the Conditioner compensating using the EPLL algorithm. This can be seen in Fig. 13. Since the distortion in $v_{L}$ increases, the series converter has to in ect more power in order to compensate it. This forces the shunt power converter of the Conditioner to drain more power to regulate the DC link. Thus, an increased system current $\left(i_{S}\right)$ is also observed. Also, the compensated $v_{L}$. THD is improved when compared with the first analysis. This is due to the increasing of $v_{\text {ref }}$ that leads to a better modulation index of the series power converter.

$$
\text { V. CO CL SIO S }
$$

A comparison between to synchronizing circuits for the control algorithm of a Series Active Converter is made in this paper.

The Single-Phase PLL presents higher memory requirements. ut given the vast amount of memory available in the selected microprocessor, this matter has a relative importance. His synchronizing circuit, however, presents higher speed performance. In a real time processing control system, this is an important advantage, since it releases time for other processing routines. In this particular, the SinglePhase PLL can overtake the Enhanced PLL. Even though the EPLL uses less memory resources, its processing time is long. Thus, one can conclude that the Single-Phase PLL is more suited for real time processing systems such as the one presented in this paper.

Experimental results also showed that the compensated load voltage $\left(v_{L}\right)$ delivered to the load is in accordance with international standards that regulate harmonic distortion and RMS value. These standards are CEI 61000 and A SI IEEE 5191992 for harmonics. For RMS value, the standard taken in account is A SI IEEE 519 1992, that describes power quality problems. This was seen on both synchronizing circuits.

\section{REFERE CES}

1 S. George, V. Agarwal, A DSP- ased Control Algorithm for Series Active Filter for Optimized Compensation nder onsinusoidal and nbalanced Voltage Conditions, IEEE Transactions on Power Delivery, Vol. 22, Issue 1, an. 2007, pp 302-310.

2 S. D okic, . Milanovic, M. McGranaghan D. Chapman, D. irschen, Shortfalls of existing methods for classification and presentation of voltage reduction events, IEEE Transactions on Power Delivery, Vol. 20, Issue 2, April 2005, pp 1640-1649.

3 os C. C. Costa, Ricardo L. Pregitzer, Tiago . Sousa, os atista, o o L. Afonso, A Case of Power uality Assessment sing a Developed Power uality Monitor, CEE 05 IEEE 1st International Conference on Electrical Engineering, Coimbra, Portugal, IS 972 99064-3-2, 1012 Out. 2005.

4 H. Akagi, . anazawa, A. abae Generalized theory of the Instantaneous reactive power in three-phase circuits in Proc. IEEE IPEC - Tokio, 1983, pp. 1375-1386.

5 M. Aredes, L. F. C. Monteiro, . M. Miguel, Control Strategies for Series and Shunt Active Filters, Power Tech Conference Proceedings, 2003 IEEE ologna, Vol. 2, 2326 une 2003, 6 pp.

6 L. F. C. Monteiro, M. Aredes, . A. Moor eto, A Control Strategy for nified Power uality Conditioner, IEEE International Symposium on Industrial Electronics, ISIE 03. 2003, Vol. 1, 911 une 2003, pp 391-396.

7 A. F. C. Aquino et al, Synchronizing Circuits Applied to on-linear Loads, 2004 IEEE PES Transmission Distribution Conference Center Conference Exposition, Latin America, pp. 700705.

8 L. G. . Rolim, D. R. da Costa r., M. Aredes, Analysis and Software Implementation of a Robust Synchronizing PLL Circuit ased on the $\mathrm{pq}$ Theory, IEEE Transactions on Industrial Electronics, Vol. 53, o. 6, December 2006, pp. 1919-1926.

9 M. arimi-Ghartemani, M.R. Iravani, F. atiraei, Extraction of signals for harmonics, reactive current and network-unbalance compensation, IEE Proceedings Generation, Transmission and Distribution, Vol. 152, Issue 1, 10 an. 2005, pp 137-143.

10 M. arimi-Ghartemani, M.R. Iravani, A onlinear Adaptive Filter for Online Signal Analysis in Power Systems Applications, IEEE Transactions on Power Delivery, Vol. 17, Issue 2, April 2002, pp 617622.

11 M. arimi-Ghartemani, M.R. Iravani, A new phase-locked loop (PLL) system , Proceedings of the 44th IEEE 2001 Midwest Symposium on Circuits and Systems, M SCAS 2001, Vol. 1, 14-17 Aug. 2001, pp 421-424.

12 . L. Afonso, H. R. Silva, lio Martins, Active Filters for Power uality Improvement, IEEE Power Tech 2001, 10-13 Set. 2001, Porto, Portugal.

13 Semikron Superfast PT-IG T Modules S M 50G 063D Data Manual, September 2006.

14 H. Akagi, H. Fu ita, A ew Power Line Conditioner for Harmonic Compensation in Power Systems, IEEE Transactions on Power Delivery, Vol. 10, Issue 3, uly 1995, pp 1570-1575. 